\title{
RELAÇÕES DE GÊNERO E EDUCAÇÃO MORAL: UMA PERSPECTIVA TRANSVERSAL PARA CONSTRUÇÃO DA PERSONALIDADE MORAL
}

\author{
Rosimeire Carvalho dos Santos Masuda, Carmen Lúcia Dias \\ Universidade do Oeste Paulista - UNOESTE, Programa de Pós Graduação em Educação, Presidente Prudente, SP. \\ E-mail: rosemasuda@hotmail.com
}

\begin{abstract}
RESUMO
As relações de gênero, histórica e culturalmente, são marcadas por desigualdades, diferenças, estereótipos, preconceitos etc. Na escola esses processos socioculturais se repetem e isso leva-nos a perceber o quão fundamental é ter uma perspectiva da escola sob a ótica do gênero. Desse modo, este artigo tem como objetivo discutir as relações sociais de gênero e educação escolar sob a perspectiva da educação moral como meio de construir personalidades morais. Para tanto, utilizamos como aporte teórico epistemológico, autores que desenvolveram estudos e dados sobre o tema de relações de gênero, educação e educação moral, possibilitando um novo enfoque através de um viés analítico. Concluímos que as relações de gênero em âmbito escolar contribuem para a manutenção da desigualdade entre os sexos e a educação moral pode ser um caminho para a construção de personalidades morais e a construção de relações de gênero democráticas.

Palavras-chave: Relações de gênero. Educação moral. Escola. Personalidade moral. Valores.
\end{abstract}

\section{GENDER RELATIONS AND MORAL EDUCATION: A CROSS-CUTTING PERSPECTIVE FOR CONSTRUCTION OF MORAL PERSONALITY}

\begin{abstract}
Gender relations, historically and culturally, are marked by inequalities, differences, stereotypes, prejudices, etc. At school these sociocultural processes repeat themselves and this leads us to realize how fundamental it is to have a school perspective from the point of view of gender. Thus, this article aims to discuss the social relations of gender and school education from the perspective of moral education as a means of building moral personalities. For that, we use as theoretical epistemological contribution, authors who have developed studies and data about gender relations, education and moral education, enabling a new approach through an analytical slant. We conclude that gender relations at the school level contribute to the maintenance of gender inequality and moral education can be a path to building moral personalities and building democratic gender relations.
\end{abstract}

Keywords: Gender relations. Moral education. School. Moral personality. Values. 


\section{INTRODUÇÃO}

O contexto em que vivemos faz parte de um longo processo histórico, social e cultural e estruturado nas relações de gênero. Se analisarmos a história podemos perceber que as relações de gênero foram construídas em torno da diferença. Historicamente coube às mulheres o espaço privado e aos homens o espaço público. O espaço privado constituiu-se em torno do âmbito familiar, do cuidado com os filhos e afazeres domésticos e o público como espaço da cidadania, do trabalho, da política, etc.

Atualmente as ideologias e as diferenças em torno do gênero ainda estão enraizadas na sociedade e se manifestam constantemente nas relações sociais de gênero. Ao longo do tempo e do espaço as mulheres conseguiram conquistar e exercer direitos de cidadania e ascender ao espaço público. No entanto, não podemos afirmar que existe igualdade entre homens e mulheres nos diversos espaços que constitui a sociedade. Embora as mulheres tenham avançado em busca de exercer sua cidadania, cabe assinalar que:

[...] é preciso reconhecer que a sociedade brasileira ainda permanece regida por uma ordem de gênero patriarcal: trata-se de uma sociedade dominada por homens, identificada com e centrada no gênero masculino, o que implica na predominância de relações assimétricas e hierárquicas entre os sexos. Essas relações desiguais se manifestam não apenas no mundo do trabalho e na arena política, como também no âmbito da família e nas relações interpessoais, expressando-se, com nitidez, na divisão sexual do trabalho. [...] Continuam, assim, vivos os valores patriarcais, sexistas, que condicionam, quando não impedem, a promoção social das mulheres. (SARDENBERG, 2011, p.17).

Embora exista um grande movimento em busca de garantir a igualdade de direitos entre homens e mulheres e tenhamos avançado nessa direção, ainda não foi possível apagar as diferenças relativas entre os sexos. A sociedade em que vivemos é constituída de estereótipos acerca da mulher que são decorrentes das relações de gênero, oposições binárias, construídas historicamente. E, certamente, o cerne das desigualdades e das diferenças entre os sexos no mundo contemporâneo.

Considera-se que as questões que permitem as relações sociais entre os sexos constituemse num arcabouço ideológico e colocam as pessoas numa relação hierarquizada. No que se refere às relações de gênero, da forma como estão configuradas na sociedade, apesar dos avanços observados nas últimas décadas, os valores predominantes ainda colocam as mulheres numa situação de subordinação, porque as diferenças biológicas são transformadas em desigualdades. (SOUZA; BRAGA; VERNI, 2010, p.76).

Destarte, é de suma importância analisar e refletir sobre as relações de gênero em nossa sociedade. Abordar o gênero como categoria de análise não é tarefa fácil, pois exige uma análise esmiuçada das relações entre homens e mulheres sob a perspectiva da diferença e das relações de poder.

O termo gênero diferente do seu uso gramatical, que é usado para definir coisas sexuadas, isto é, masculino e feminino, nas ciências sociais tem um significado bem diferente. $O$ gênero como categoria de análise ganhou espaço com os pós-estruturalistas que buscaram uma forma de analisar as relações entre homens e mulheres sob a ótica nas diferenças constituídas ao longo do tempo e do espaço. Assim, o termo gênero é definido como uma categoria analítica que não se restringe a uma variável sobre o feminino e o masculino, mas a uma construção social, histórica e cultural que permeia as relações entre o homem e a mulher. Isto é, um termo usado para teorizar as relações sociais entre ambos os sexos ao longo do tempo e do espaço, também, as diferenças e relações de poder entre os sexos (BRITO, 2011; DEL PRIORE, 2001; SCOTT, 1992; SOIHET; PEDRO, 2007).

Isso quer dizer que para compreendermos o gênero de forma ampla é preciso, segundo Louro (1995, p.103): 
[...] que pensemos não somente que os sujeitos se fazem homem e mulher num processo continuado, dinâmico (portanto não dado e acabado no momento do nascimento, mas sim construído através de práticas sociais masculinizantes e feminizantes, em consonância com as diversas concepções de cada sociedade); como também nos leva a pensar que gênero é mais do que uma identidade aprendida, é uma categoria imersa nas instituições sociais (o que implica admitir que a justiça, a escola, a igreja, etc. são 'generificadas', ou seja, expressam as relações sociais de gênero).

Ao percebermos que as relações de gênero fazem parte do nosso contexto, podemos afirmar que elas podem ser percebidas nos diversos espaços e estruturas que constituem a sociedade. Partindo desse princípio, nota-se que o âmbito educacional se constitui em um espaço às relações de gênero.

A escola ocupa papel importante nesse contexto, pois nela, de acordo com Maia, Navarro e Maia (2011), podemos notar vários mecanismos que contribuem e estabelecem padrões comportamentais e hierarquias sociais entre meninos e meninas.

Conforme Costa, Rodrigues e Vanin (2011, p.7):

Apesar do acelerado processo de democratização do ensino e da construção de modernas práticas pedagógicas, a escola segue sendo uma instituição que cria, reproduz e alimenta, através do processo de socialização/educação, ideologias e práticas discriminatórias excludentes. Desde o surgimento da escola, o cotidiano escolar se encarregou de trazer consigo uma práxis que divide, separa e discrimina, tanto internamente quanto externamente, encarregando-se de apartar os sujeitos, através de múltiplos mecanismos de classificação, ordenamento e hierarquização, a exemplo das classificações baseadas no gênero, na classe e na raça/etnia.

Diante do exposto, este artigo tem como objetivo discutir as relações sociais de gênero e educação escolar sob a perspectiva da educação moral como meio de construir personalidades morais.

\section{METODOLOGIA}

A pesquisa teve como aporte teórico-epistemológico (SEVERINO, 2007), autores que desenvolveram estudos e dados sobre o tema de relações de gênero, educação e educação moral, possibilitando, através de um viés analítico, um novo enfoque sobre o tema.

\section{DISCUSSÃO}

A escola é vista como um espaço de heterogeneidade, ou seja, é composta por diferentes identidades que trazem consigo um contexto sociocultural diversificado, portanto, ideias, valores, crenças, padrões, entre outros, que estão em constante contato, daí, resultando em mudanças de ideias, comportamentos ou até mesmo contribuindo para a manutenção e propagação de valores, padrões rígidos de pensamento levando à desigualdade, ao preconceito e à discriminação.

As identidades são construídas por meio das relações sociais, pois:

[...] O ser humano por sua própria condição humana vive e age em situação social. Ademais, sua linguagem, sua forma de pensar, de sentir e de julgar são fruto da história de suas relações com a natureza e com os outros homens. É no contexto da convivência que se abrem para ele todas as possibilidades, mas também se impõem os limites e as normas. (GOERGEN, 2005, p.25).

Segundo Souza e Araujo (2012, p.1), a identidade pode ser definida:

[...] como um conjunto de representações de si que agregam valores (morais ou não) e como ele se articula com as transformações sociais, permitindo aproximações e distanciamentos entre pessoas e/ou grupos. Assim, semelhanças e diferenças se forjam a partir da produção de identidades pessoais e grupais, delineando relações de 
estranhamento e de pertença, cuja tensão pode desencadear ações cooperativas/colaborativas e/ou de violência e/ou indiferença.

O âmbito escolar pode ser percebido como espaço de reprodução de identidades individuais e grupais com pensamentos binários, que se constituem através de ideias, valores, representação, discriminação, estereótipos, em torno das relações de gênero. Isso leva-nos a perceber o quão fundamental é ter uma ótica da escola como espaço de diversidade e desigualdade.

Conforme Maia, Navarro e Maia (2011, p.26) “[...] nosso sistema educacional colabora com a manutenção de ideias obsoletas em relação às identidades pessoais, baseadas em critérios fixos acerca das possibilidades de ação, pensamento e personalidade de mulheres e homens [...]."

Ainda, segundo Sardenberg e Macedo (2011):

A educação formal nas escolas contribui para essa diferenciação sexual de papéis, a começar pelo fato de que a esmagadora maioria dos professores primários é constituída por mulheres, chamadas familiarmente de "tias", o que reflete ser essa ocupação, feminina, uma extensão das atividades domésticas. Ademais, os livros didáticos reforçam os estereótipos e as próprias professoras punem muito mais as meninas que não se comportam, dando maior latitude de expressão para os meninos. [...] É claro que tudo isso é interiorizado por meninos e meninas, contribuindo para que quando cheguem à idade adulta, homens e mulheres se vejam como essencialmente diferentes, pensem e se comportem, de fato, de forma diferente, o que reforça as noções de que as diferenças observadas são "naturais" aos sexos. (SARDENBERG; MACEDO, 2011, p.41-42).

Por isso, é fundamental percebermos como as relações de gênero são construídas no âmbito escolar, na sala de aula, no currículo, no processo de ensino-aprendizagem. Para haver transformações nas relações sociais de gênero na escola é importante darmos ênfase ao processo de ensino-aprendizagem, adotar uma postura crítica e não de neutralidade ou indiferença, a começar pela seleção dos materiais a serem trabalhados em sala de aula, os livros didáticos, jornais, revistas, vídeos, jogos, brincadeiras, etc., uma série e materiais que podem conter mensagens sexistas e corroboram com a representação estereotipada de mulheres e homens (MAIA; NAVARRO; MAIA, 2011).

De acordo com Sardenberg e Macedo (2011, p.39):

A adoção de um recorte transversal em torno das relações de gênero funciona como uma lente que possibilita a visibilização de uma série de aspectos que a sociedade vem naturalizando e que vem assegurando a perpetuação de relações assimétricas entre homens e mulheres. A partir dos "filtros de gênero", torna-se perceptível que as mulheres não dispõem das mesmas condições que os homens para enfrentar os problemas da vida cotidiana [...].

A educação quando está relacionada ao gênero deve ser vista como instrumento de reflexão crítica acerca dos conceitos construídos pelos indivíduos, das práticas sociais, pedagógicas e discursivas entre os envolvidos com a educação.

[...] pensar a educação escolar sob a ótica do gênero permite tecer novos caminhos no processo de ressignificação de categorias aparentemente universais. Há de se atentar para que as multiplicidades sejam observadas, visibilizando e compreendendo as relações mais finas [...]. Assim, adotar o gênero pode indicar a possibilidade de romper com pensamentos binários que insistem em formas dicotômicas e hierarquizadoras, como branco ou negro; homem ou mulher; cultura ou natureza. (JARDIM; ABRAMOWICZ, 2005, p. 95-96).

Destarte, para que haja mudanças nas relações de gênero é primordial adotar práticas que promovam a equidade, a construção de relações democráticas e de sujeitos éticos e agreguem 
valores universais. Um caminho a promover estas transformações pode ser possível por meio da educação moral.

De acordo com Goergen (2005), a formação moral leva em conta aspectos desde a incorporação das convenções sociais até a formação da consciência moral autônoma, adquiridos através da reflexão e das atitudes pessoais pela educação formal ou informal e pela interação sociocultural.

A educação moral pode ser entendida como um dos aspectos da educação integral, que abrange a educação corporal, a educação intelectual, a educação afetiva, a educação artística [...]. A educação ocupa um lugar de destaque porque pretende dar uma orientação e um sentido ao ser humano como um todo; ela, de certo modo, perpassa transversalmente todas as dimensões da formação humana. (GOERGEN, 2005, p.24).

A educação moral pode ser um caminho para construção do sujeito moral através um recorte transversal e ser um eixo de articulação do tema diversidade na escola, viabilizando a problematização das diferenças hierarquizadas, promovendo a percepção e a consciência dos diferentes sujeitos e identidades respeitando-as sem restringir os direitos dos outros (SOUZA; ARAUJO, 2012, p.5).

Ademais, sobre a educação moral "[...] pode-se dizer que sua influência educativa deve contribuir para um sujeito consciente e autônomo, capaz de decidir que atitudes tomar que, na busca da felicidade, preservem tanto interesses individuais quanto sociais." (GOERGEN, 2005, p.25).

O trabalho com a educação moral pode ser desenvolvido de diversas formas. No entanto, a perspectiva da educação como construção da personalidade moral é apontada como possível referência para a abordagem de diversidade de gênero e sexual na escola, pela perspectiva dialógica da construção da moralidade aproximar-se de paradigmas contemporâneos. (SOUZA; ARAUJO, 2012).

Dessa maneira, cabe ressaltar que ao se adotar uma perspectiva de educação moral é importante levar em conta o contexto em que o educando está inserido, partindo de dilemas e conflitos que fazem parte da sua realidade, como os temas e conflitos sobre as relações de gênero sob a ótica de valores universalmente desejáveis. Assim, conforme Souza e Araujo (2012, p.5):

[...] A ética e a moral são temas da prática. Esse é o desafio: compreender a educação moral a partir das experiências e condições concretas de vida, questionando as formas de pensar, sentir e agir diante da diferença; produzir novas formas de pensar, sentir e agir oriundas da articulação de questões individuais, tais como necessidades e desejos, bem como projetos e valores coletivos.

A educação moral e ética pode viabilizar os espaços de problematização sobre a diversidade (de ideias, valores, cultura, linguagem, afetos, etc.) com a finalidade de negociar significados e sentidos na direção de princípios comuns para as relações sociais, extrapolando a vida escolar. Pode auxiliar na superação da reprodução das relações sociais ao considerar as diferenças para problematizar as condições concretas de vida das pessoas.

A educação moral pode ser um importante instrumento na formação de indivíduos morais, pois possibilita a percepção e a conscientização do outro e das relações sociais e, assim, através do respeito aos direitos e deveres do indivíduo, contribuir para uma sociedade democrática.

Assim, de acordo com Goergen (2005), os conteúdos morais promoveriam a atitude moral que levaria o sujeito a ter a consciência de decidir a melhor maneira de agir em prol de si e da sociedade. As decisões morais possibilitam a escolha de um caminho desejável e o socialmente justo, isto é, em busca de um meio a alcançar proposições adequadas paras os indivíduos e para a coletividade. 


\section{CONCLUSÃO}

Percebemos que as relações de gênero fazem parte do processo educativo e se desenrolam na escola, por isso, é necessário adotar práticas pedagógicas visando a interrelação entre diferentes grupos e sujeitos que integram a escola, por meio de um currículo que integre no cotidiano do educando temas que estão imbricados a sua realidade, como as relações sociais de gênero, por exemplo. É importante percebermos o processo de ensino-aprendizagem como meio de superação das desigualdades de gênero e o (a) professor (a) como figura fundamental nesse processo. Neste contexto, entra a função pedagógica do (a) professor (a) como meio de superar as desigualdades de gênero, as diferenças, os valores, os estereótipos que estão arraigados em nossa sociedade, muitas vezes, naturalizados e não questionados.

Nesta perspectiva, podemos destacar a importância do recorte transversal da educação moral como possibilidade de construção da personalidade moral e da construção de valores éticos universalmente desejáveis. Para isso, é fundamental que a educação moral na escola tenha como ponto de partida os temas e conflitos acerca das diferenças de gênero, através de atividades que proporcionem aos educandos diferentes situações de experiências morais pautadas na dimensão da identidade /alteridade na construção das personalidades éticas por meio de valores que tenham como base a convivência, a tolerância, o respeito em relação ao gênero.

Contudo, é necessário perceber que o gênero como categoria de análise em âmbito educacional promove uma reflexão sobre os padrões, a exclusão e a distinção entre homens e mulheres. Ademais, perceber a escola em uma perspectiva transformadora acerca das relações de gênero é fundamental, pois a educação escolar tem papel importante na formação dos cidadãos e pode ser vista como meio de subverter as convenções e possibilitar o desenvolvimento de uma ótica crítica acerca dos padrões construídos e romper com o pensamento binário que perpetuam e contribuem para o posicionamento hierárquico acerca do gênero na sociedade.

\section{REFERÊNCIAS}

BRITO, Maria Noemi. O gênero, a história das mulheres e a memória: um referencial de análise. Disponível em: <http://www.lacult.unesco.org/docc/oralidad_05_22-27-o-genero-a-historiadas.pdf >. Acesso em: 13 jul. 2017.

COSTA, Ana Alice Alcantara; RODRIGUES, Alexnaldo Teixeira; VANIN, lole (Org.). Ensino e Gênero: Perspectivas Transversais. Salvador: UFBA - NEIM, 2011. p.7-16.

DEL PRIORE, Mary. História das mulheres: as vozes do silêncio. In: FREITAS, Marcos Cezar de; SOUZA, Laura de Mello e. Historiografia brasileira em perspectiva. São Paulo: Contexto, 2001. p.217-235.

GOERGEN, Pedro. Educação e valores no mundo contemporâneo. Educação \& Sociedade, Campinas, v. 26, n. 92, p.983-1011, Especial-Out. 2005. Disponível em: <http://www.cedes.unicamp.br>. Acesso em: 18 abr. 2018.

JARDIM, S. R. M. ABRAMOWICZ, A. Tendências da produção paulista sobre gênero e educação: um balanço de dissertações de mestrado. RBPG, v. 2, n. 3, p. 93-117, mar. 2005. Disponível em: <http://ojs.rbpg.capes.gov.br/index.php/rbpg/article/view/61>. Acesso em: 15 jul. 2017.

LOURO, Guacira Lopes. Gênero, história e educação: construção e desconstrução. Educação \& Realidade, v. 20, n. 2, p.101-132, jul./dez. 1995. Disponível em: <http://seer.ufrgs.br/index.php/educacaoerealidade/article/view/71722>. Acesso em: 15 jul. 2017. 
MAIA, A. C. B. NAVARRO, C. MAIA, A. F. Relações entre gênero e escola no discurso de professoras do ensino fundamental. Psicologia da Educação, São Paulo, n.32, p. 25-46, 10 sem. 2011. Disponível em: <http://pepsic.bvsalud.org/scielo.php?script=sci_arttext\&pid=S141469752011000100003>. Acesso em: 19 jul. 2017.

SARDENBERG, Cecília M. B. Considerações introdutórias às pedagogias feministas. In: COSTA, Ana Alice Alcantara; RODRIGUES, Alexnaldo Teixeira; VANIN, Iole (Org.). Ensino e Gênero: Perspectivas Transversais. Salvador: UFBA - NEIM, 2011. p.17-32.

SARDENBERG, Cecília M. B.; MACEDO, Márcia S. Relações de gênero: uma breve introdução ao tema. In: COSTA, Ana Alice Alcantara; RODRIGUES, Alexnaldo Teixeira; VANIN, Iole (Org.). Ensino e Gênero: Perspectivas Transversais. Salvador: UFBA - NEIM, 2011. p.33-48.

SCOTT, Joan. História das mulheres. In.: BURKE, Peter (Org.). A escrita da história: novas perspectivas. São Paulo: Editora UNESP, 1992, p. 63-95.

SEVERINO, Antônio Joaquim. Metodologia do trabalho científico. 23. ed. São Paulo: Cortez, 2007.

SOIHET, Rachel; PEDRO, Joana Maria. A emergência da pesquisa da História das Mulheres e das Relações de Gênero. História e gênero, São Paulo, v. 27, n. 54, p. 281-300, dez. 2007. Disponível em: <http://www.scielo.br/pdf/rbh/v27n54/a15v2754.pdf>. Acesso em: 13 jul. 2017.

SOUZA, Leonardo Lemos de; ARAUJO, Ulisses Ferreira. Educação moral e diversidade nas escolas: problematizações sobre gênero e sexualidades. Revista Ibero-americana de Educação, v.59, n.4, ago. 2012. Disponível em: <https://rieoei.org/RIE/article/view/1346 >. Acesso em: 02 jul. 2018.

SOUZA, M. M. L.; BRAGA, S. A. L.; VERNI, M. L. Gênero e educação: um estudo de interpretação de gênero e discriminação no magistério feminino em escolas públicas do paraná. In: PEIXE, Blênio César Severo [et al.]. Formulação e Gestão de Políticas Públicas no Paraná: reflexões, experiências e contribuições. Paraná: Imprensa Universitária da Universidade Federal do Paraná, 2010. p.73-88. Disponível

em:

<http://www.escoladegestao.pr.gov.br/modules/conteudo/conteudo.php?conteudo=541>. Acesso em: 14 jul. 2017. 